CAHIER DE RECHERCHE \#0808E

Département de science économique

Faculté des sciences sociales

Université d'Ottawa
WORKING PAPER \#0808E

Department of Economics

Faculty of Social Sciences

University of Ottawa

\title{
Can Risk Averse Competitive Input Providers Serve Farmers Efficiently in Developing Countries
}

\author{
Paul Makdissi* and Quentin Wodon $^{* *}$
}

July 2008

\footnotetext{
\# The opinions expressed here are those of the authors and need not represent those of the World Bank, its Executive Directors, or the countries they represent.

* Department of Economics, University of Ottawa, 55 Laurier E. (10125), Ottawa, Ontario, Canada, K1N 6N5;

Email: paul.makdissi@uottawa.ca.

A** AFTPM, World Bank, 1818 H Street, NW, Washington, DC 20433, USA, Email: qwodon@worldbank.org.
} 


\begin{abstract}
Under price ceilings and quality floors for agricultural inputs in cash crop sectors in developing countries where credit markets are weak, imperfect information on the ability of farmers to pay for their inputs at the end of the cropping season may lead the decentralized production of those inputs by risk averse private input providers to be inefficient. A coordinating agency and/or subsidies for new farmers could help to produce and distribute more agricultural inputs, thereby increasing the profits for input providers while also enabling more farmers to produce the crops that are key to their livelihood.
\end{abstract}

Keywords: Farm inputs, Risk Aversion, Price Control, Public Good.

JEL Codes : H41, Q12

\title{
Résumé
}

Nous modélisons le secteur des cultures de rentes dans les pays en développement pour lesquels les marchés de crédits sont peu développés. Sous un régime de prix plafond et de plancher de qualité pour les intrants agricoles, nous montrons qu'une information imparfaite sur l'aptitude du fermier à payer les intrants è la fin de la saison des récoltes peut entraîner une inefficacité dans l'allocation obtenue par un marché décentralisé des intrants. Une agence de coordination et/ou des subsides aux nouveaux fermiers peut aider à produire plus d'intrants, augmenter les profits des producteurs d'intrants et augmenter la production des fermiers.

Mots-clé: Intrants agricoles, aversion au risque, contrôle des prix, bien public Classification JEL: H41, Q12 


\section{Introduction}

In West Africa as in other parts of the developing world, there has been a push towards the privatization of state-owned enterprises in order to improve productive efficiency and promote competition. This drive towards privatization has affected among others agricultural sectors such as cotton (in Benin, but also in Mali and Burkina Faso), cocoa (in Cote d'Ivoire and Ghana), and groundnut (in Senegal). Many of these sectors used to follow the French-based "filière integrée" model, whereby a single parastatal firm provided inputs to farmers such as seeds and fertilizers at the beginning of the cropping season, and then purchased the production of these farmers at the end of the season, with the price paid to producers being net of the value of the inputs provided earlier in the season (on the French filière integrée, see for example Raikes et al., 2000).

One key rationale for this integrated model was the fact that credit markets are weak in developing countries so that farmers cannot easily obtain credit to purchase the inputs they need for their production 1 . By contrast, when a single parastatal purchases all of the production of a given crop, there is obviously an incentive for that parastatal to provide the inputs required by farmers to produce the crop, as well as an ability for the prastatal to deduct the price of the inputs from the payment made to farmers for their crop.

Despite some advantages of the integrated model, privatization was advocated in order to promote competition, increase efficiency, and hopefully generate higher prices for crop producers, as well as in order to reduce risks of corruption related to the close links that used to exist in some countries between some parastatals and political parties. In practice, privatization has meant that at the input and output stages, multiple input providers as well as crop purchasers have been allowed to enter previously closed makets.

The jury is still out in practice as to whether the move towards privatization has been beneficial or not (e.g., Goreux, 2003; Badiane et al., 2002; Akiyama et al., 2003; Poulton et al., 2003; Siaens and Wodon, 2008) $\quad$ It is not surprising that empirical evidence is inconclusive as to the impact of privatization on farmers since theoretically as well, it is unclear whether privatization should benefit farmers or not. In previous work (Makdissi and Wodon, 2005), we compared the system of an integrated firm supplying inputs and purchasing crops to a privatized system with contract farming under which each farmer

\footnotetext{
${ }^{1}$ There is a large literature on credit markets for farmers in developing countries. For recent work on the issue of risk, see among others Boucher and Guirkinger (2007), and Boucher et al. (2008).

${ }^{2}$ In the case of Zimbabwe which privatized its cotton sector earlier on, the impact of competition has been mixed despite initial success, in part due to difficulties in coordinating the actions of the various actors and maintaining quality standards (e.g., Gibbon, 1999; Larsen, 2002 and 2003).
} 
negotiates its own contract, with the possibility of different farmers paying different prices for their inputs and receiving different prices for their crops. Our model suggested that privatization could be beneficial to some farmers, while being detrimental to other 3 .

In this paper, our objective is to suggest a different theoretical argument as to why privatization of input provision in agricultural sectors may actually lead to a loss in efficiency, rather than a gain. Our argument is based on the difficulty to identify "good" from "bad" farmers in terms of their ability to pay at the end of the cropping season for the inputs received at the beginning of the season. In a privatized and decentralized system, new and younger farmers who haven't yet proven their ability to pay the inputs that they receive at the end of the season are more risky to deal with for input providers than farmers who have already proven themselves and have a good "credit record".

If input provision markets were fully flexible, the prices paid by farmers for their inputs or the quality of the inputs provided to them would adjust to fully take into account the repayment risks and the limited information available to input providers. But in the agricultural input markets in developing countries, the prices to be paid for inputs can be subject to ceilings (negociated between producer organizations, input providers and the state), and the inputs (such as seeds) provided must respect minimal quality standards, so that costs for input providers are subjects to floors. In such circumstances there may be cases under which the decentralized provision of agricultural inputs by private providers will not be efficient. This is because the production of information on the quality of the farmers in terms of their ability or willingness to pay for inputs (i.e., who pays and who does not pay the inputs at the end of the cropping season, when farmers actually have resources to pay) is a public good that will not be fully taken into account by private input providers in their own optimization function 4 .

\footnotetext{
${ }^{3}$ On the input side, whether a farmer will benefit or not from privatization depends on the farmer's elasticity of demand for inputs and the number of input providers. Similarly, on the output side, the farmer's elasticity of supply of cotton and the number of cotton purchasers will determine whether the farmer will benefit from privatization. Farmers with a low elasticity of demand for inputs and a low elasticity supply of outputs are more likely to be hurt by privatization than farmers with higher elasticities. More generally, on the experience with contract farming in Africa, see Porter and Phillips-Howard (1997). For a survey on the potential gains and losses from agricultural concentration, see Whitley (2003).

${ }^{4}$ A similar point was made by Makdissi and Tejedo (2004) in the case of labor markets. Indeed, the argument made in this paper is similar to an argument made in the employment literature which points out to the fact that there is a cost for firms to match their needs with the workers that they are hiring (Jovanovic, 1979; Miller, 1984). This matching process is imperfect as firms do not have full information on the future level of productivity of the workers that they are hiring. This leads many firms to hire workers, and then fire some of them (those who proved less productive) in order to hire new workers who may not appear very different on the basis of their observable characteristics from the workers who just lost their job. As noted by McCall (1991), the issue of matching workers with jobs is more problematic for younger workers who lack experience and have not yet proven themselves. For more experienced workers, their
} 
The model presented in this paper shows that input providers may produce or make available inputs at a level at which the cost of producing and distributing new inputs will be below the expected benefit to them from selling these inputs. By contrast, a coordinating agency might better take the public good nature of the information on the quality of farmers in terms of their repayment ability into account, and this would result in a higher level of production of inputs which will benefit farmers, as well as in higher profits for input providers. In the absence of such a coordinating agency, production or other subsidies for input providers could make sense on efficiency grounds apart from the more traditional equity arguments advanced sometimes in the literature given the benefits of higher availability of inputs for farmers. In other words, equity considerations would not be the only argument in favor of government subsidies or intervention in the agricultural input provision market.

\section{Model and Results}

Consider input providers who maximize their actualized expected VNM (Von NeumanMorgenstern) utility of income over an infinite time horizon ${ }^{5}$, A slightly simpler model could be written in a two-periods framework, but for the sake of generality, we will use an infinite horizon. The input providers derive their income from providing farm inputs to small scale farmers at the beginning of the cropping season, with payment at the end of that season.

The market is regulated so that there is a maximum price or fee that can be charged to farmers for those inputs, which is denoted by $f$. Assume that each farmer uses only one unit of input and that those inputs are produce by a constant return to scale production function. In this context, the cost for producing the inputs for $n$ farmers is given by $c \cdot n$. The input providers face non-payment issues among the farmers. Only a proportion $p \in[\underline{p}, 1]$ of new farmers (i.e. farmers who are receing inputs for the first time) pay for the inputs at the end of the cropping season. This proportion $p$ is unknown a priori. If $F(\cdot)$ represents the cumulative distribution function of $p$ over the interval $[\underline{p}, 1]$, then its expected value is $\mu=\int_{\underline{p}}^{1} p d F(p)$. We also assume that $\underline{p} f>\mu c$, otherwise the market for inputs may vanish.

The input providers are risk averse, so that their preferences may be represented by

past successful record of employment is a signal that firms can use in order to minimize the risks associated with hiring new workers. Note that this signal on individual worker quality is available to all firms, not only to those that employed these more successful workers, since on the labor market workers make their employment record public.

${ }^{5}$ Assume for example that at time $t=0$, the input provider is a dynasty head who cares for the welfare of his offspring. In this context, the discount factor $\beta$ incorporates time preference as well as altruism. 
a Bernoulli utility function $u(\cdot)$ with standard assumptions $u^{\prime} \geq 0$ and $u^{\prime \prime}(\cdot) \leq 0$. The hypothesis of risk aversion is necessary in order for the input providers to prefer to have more information on the quality (in terms of payment for the inputs) of the farmers and thereby reduce the risk of providing inputs to farmers which would turn out not to pay for these inputs at the end of the cropping season.

Farmers live (and thereby receive inputs) for two periods. In the first period, they obtain inputs for the first time, so that input providers do not have any specific information on the probability that they will pay for the inputs received at the end of the cropping season. In the second period however, the farmers have the equivalent of a credit rating record, so that any input provider will know if they have been good at paying their inputs or not in the previous period (the fact that there is a credit rating system means that the information on the quality of the farmers is available to all input providers, not only to the provider who sold inputs in the first period to any particular farmer). At any given time $t$, an input provider will sell inputs to both new (first period) and old (second period) farmers.

The number of input providers is $K>1$. As already mentioned, the input providers cannot identify the quality of new, first period farmers. New farmers are therefore chosen randomly. After one period, "bad" farmers loose the ability to purchase input since they did not pay for these inputs in the previous period, while the identity of "good" farmers is common knowledge through the equivalent of the credit rating system. Let $n_{t}^{i}$ be the number of new farmers chosen by input provider $i$ at time $t$ and let $\eta_{t}^{i}$ be the number of good farmers among them. If the number of input providers is large, we can use the following approximation

$$
\sum_{i=1}^{K} \eta_{t}^{i}=\mu \sum_{i=1}^{K} n_{t}^{i}
$$

At the end of each period, good farmers are equally distributed among each input provider. We will assume that the fee paid for the inputs by good farmers is at the maximum admissible value $f$. We could also assume that input providers wishing to keep good farmers will offer a reduction in fees in the second period, but this would not change the key results. What matters is that at the equilibrium, each input provider will ask for the same fee and good farmers will be distributed equally among all input providers. Specifically, each input provider will have $\eta_{t-1}$ good farmers at time $t$ with $\eta_{t-1}=(\mu / K) \sum_{i=1}^{K} n_{t-1}^{i}$.

Assume now that there exist $\eta_{-1}$ good farmers at time 0 . For input provider $i$, the optimization problem is 


$$
E u^{i}=\max _{\left\{n_{t}^{i}\right\}_{t=1}^{\infty}} \sum_{t=0}^{\infty} \beta^{t} \int_{0}^{1} u\left(\eta_{t-1} f+p n_{t}^{i} f-c \cdot\left(\eta_{t-1}+n_{t}^{i}\right)\right) d F(p),
$$

where $E u^{i}$ represents the input provider's expected utility and $\beta$ is the discount factor. Using (1) in (2), we can rewrite the problem as

$$
E u^{i}=\max _{\left\{n_{t}^{i}\right\}_{t=1}^{\infty}} \sum_{t=0}^{\infty} \beta^{t} \int_{0}^{1} u\left(\mu \frac{\sum_{k=1}^{K} n_{t-1}^{k}}{K} f+p n_{t}^{i} f-c \cdot\left(\mu \frac{\sum_{k=1}^{K} n_{t-1}^{k}}{K}+n_{t}^{i}\right)\right) d F(p) .
$$

Consider now the open loop Nash equilibrium of this problem. The steady-state equilibrium values are given by

$$
\begin{aligned}
0= & \int_{0}^{1} u^{\prime}\left(\widehat{n}^{*} f[\mu+p]-c \cdot\left(\widehat{n}^{*}[1+\mu]\right)\right)(p f-c) d F(p) \\
& +\frac{\beta \mu}{K}(f-c) \int_{0}^{1} u^{\prime}\left(\widehat{n}^{*} f[\mu+p]-c \cdot\left(\widehat{n}^{*}[1+\mu]\right)\right) d F(p)
\end{aligned}
$$

The interpretation of (4) is that input providers equalize the expected marginal benefits from identified good farmers in the second period, $\frac{\beta \mu}{K}(f-c) \int_{0}^{1} u^{\prime}(\cdot) d F(p)$, with the expected marginal cost of identifying those farmers, $-\int_{0}^{1} u^{\prime}(\cdot)(p f-c) d F(p)$.

An alternative to the decentralized functioning of the market would be to have some agency intervening in order to maximize the joint expected utility of all input providers taken at once, by maximizing the following aggregate utility function

$$
\sum_{k=1}^{K} E u^{k}=\max _{\left\{\left\{n_{t}^{i}\right\}_{t=1}^{\infty}\right\}_{i=1}^{K}} \sum_{i=1}^{K} \sum_{t=0}^{\infty} \beta^{t} \int_{0}^{1} u\left(\mu \frac{\sum_{k=1}^{K} n_{t-1}^{k}}{K} f+p n_{t}^{i} f-c \cdot\left(\mu \frac{\sum_{k=1}^{K} n_{t-1}^{k}}{K}+n_{t}^{i}\right)\right) d F(p) .
$$

The steady-state equilibrium of this problem is given by

$$
\begin{aligned}
0= & \int_{0}^{1} u^{\prime}\left(\widetilde{n}^{*} f[\mu+p]-c \cdot\left(\widetilde{n}^{*}[1+\mu]\right)\right)(p f-c) d F(p) \\
& +\beta \mu(f-c) \int_{0}^{1} u^{\prime}\left(\widetilde{n}^{*} f[\mu+p]-c \cdot\left(\widetilde{n}^{*}[1+\mu]\right)\right) d F(p)
\end{aligned}
$$

By comparing (4) and (6), we can see that individual input providers only consider their own expected marginal benefit in the second period when optimizing their behavior, $\frac{\beta \mu}{K}(f-c) \int_{0}^{1} u^{\prime}(\cdot) d F(p)$, while the coordinating agency takes into account the expected marginal benefit of all input providers taken together, namely $\beta \mu(f-c) \int_{0}^{1} u^{\prime}(\cdot) d F(p)$. We can now state a first result.

Lemma 2.1 If the input providers cannot identify the quality of new farmers, the decentralized allocation does not maximize joint profits. 
Proof. Assume that $\widehat{n}^{*}=\widetilde{n}^{*}=n^{*}$. Let

$$
X=\int_{0}^{1} u^{\prime}\left(n^{*} f[\mu+p]-c \cdot\left(n^{*}[1+\mu]\right)\right)(p f-c) d F(p)
$$

and

$$
Y=(f-c) \int_{0}^{1} u^{\prime}\left(n^{*} f[\mu+p]-c \cdot\left(n^{*}[1+\mu]\right)\right) d F(p)
$$

Equations (4) and (6) can be rewritten as

$$
X+\frac{\beta \mu}{K} Y=0
$$

and

$$
X+\beta \mu Y=0 .
$$

Those two equations are both valid if and only if

$$
\frac{\beta \mu}{K}=\beta \mu \text {. }
$$

This implies that $K$ must be equal to 1 , which is a contradiction since we have more than one input providers, hence $\widehat{n}^{*} \neq \widetilde{n}^{*}$

Note that if the number of farmers at the Nash equilibrium does not maximize joint firm profits, this does not imply that it does not maximizes welfare. The lemma simply states that the number of farmers is not optimal from the point of view of the input providers. However, if this non-optimality from the point of view of input providers leads to a lower number of farmers, then we can sate that the equilibrium provides a lower level of welfare than would be feasible under a different arrangement, so that a Pareto improvement is possible. The next proposition analyzes what happens in the specific case when we move toward a perfectly competitive market for input provision.

Proposition 2.1 In a perfect competition framework $(K \rightarrow \infty)$, the number of new farmers is lower than under central coordination of input provision.

Proof. If $K \rightarrow \infty$, equation (4) may be rewritten as

$$
\int_{0}^{1} u^{\prime}\left(\widehat{n}^{*} f[\mu+p]-c \cdot\left(\widehat{n}^{*}[1+\mu]\right)\right)(p f-c) d F(p)=0
$$

Now assume that $\widetilde{n}^{*}<\widehat{n}^{*}$. This implies that

$$
\int_{0}^{1} u^{\prime}\left(\widetilde{n}^{*} f[\mu+p]-c \cdot\left(\widetilde{n}^{*}[1+\mu]\right)\right)(p f-c) d F(p)>\int_{0}^{1} u^{\prime}\left(\widehat{n}^{*} f[\mu+p]-c \cdot\left(\widehat{n}^{*}[1+\mu]\right)\right)(p f-c) d F(p)=0
$$


We know that $\beta \mu(f-c) \int_{0}^{1} u^{\prime}\left(\widetilde{n}^{*} f[\mu+p]-c \cdot\left(\widetilde{n}^{*}[1+\mu]\right)\right) d F(p)>0$, so equation 6 implies

$$
\int_{0}^{1} u^{\prime}\left(\widetilde{n}^{*} f[\mu+p]-c \cdot\left(\widetilde{n}^{*}[1+\mu]\right)\right)(p f-c) d F(p)<0 .
$$

Given that it is impossible to have jointly equations 13 and (14), $\widetilde{n}^{*}$ cannot be strictly lower than $\widehat{n}^{*}$. From Lemma 2.1, we know that $\widetilde{n}^{*}$ cannot be equal to $\widehat{n}^{*}$. This implies that $\widetilde{n}^{*}>\widehat{n}^{*}$.

This situation is somewhat similar in spirit to Hardin's (1968) "tragedy of the commons" for renewable natural resources for which there is free access. Here, the common resource is the pool of identified good farmers to which all input providers have free (or quasi free) access. In the case of natural resources, the situation leads to over-extraction of the resources, while in our case, there is under-production of the common resource represented by the information on good farmers. If the demand for inputs on the part of farmers is inelastic (everybody needs inputs in order to be able to produce their crops), the decentralized provision by risk averse input providers does not maximize social welfare. Said differently, a coordinating agency would not only enable input providers to maximize their profit, but it would also increase social welfare by increasing consumer surplus, since a larger number of farmers would be consumers of the inputs provided by input providers.

\section{Conclusion}

Many developing countries have privatized their integrated agricultural production systems with the hope that this would increase efficiency in the production of export crops such as cotton, cocoa, coffee and groundnut. We have shown in this paper that privatization may lead to inefficiency instead under the (realistic) assumption that risk is involved in the provision of inputs to farmers at the beginning of a cropping season, as some farmers may not be able or willing to pay for their inputs at the end of the season when they sell their outputs. More precisely, we have outlined a simple model under which the provision of inputs by risk averse private input providers is inefficient, as the marginal benefit from providing additional inputs to the market would more than compensate for the cost of making these additional inputs available to farmers.

A coordinating agency which would take into account the information generated by farmers on their ability to pay for their inputs at the end of the cropping season would help to produce more inputs, and it would do so in a profitable way. In the absence of such a coordinating agency, the information generated in the first period on the quality of the new 
farmers is a public good which is not fully taken into account in the maximization behavior of decentralized input providers.

It should be emphasized that the lack of efficiency arises in large part because both the fees or prices to be paid for the inputs by farmers and the quality of the inputs to be provided to them are regulated in the model. If we assume that farmers have an inelastic demand for inputs (all farmers need the inputs to produce their crops and this production is key to their livelihood), prices would adjust upward to clear the market if there were no ceiling on the maximum admissible fees or prices for the inputs. Alternatively, the production cost of the inputs could adjust downward (through lower quality) in order to clear the market at the fee ceiling. Yet in the farm input market in developing countries for crops such as cotton, coffee, cocoa, or groundnut, we do typically have both price or fee ceilings for inputs and quality floors, so that the markets may indeed not clear as they are supposed to.

The results of our model should not be interpreted as suggesting that privatization should not be implemented in agricultural sectors in sub-Saharan Africa and elsewhere as there may be good reasons for pursuing the privatization agenda which have nothing to do with the issue discussed here. Instead, the potential implication of our model is that in the absence of a coordinating agency (or if creating such an agency is not feasible), governments willing to minimize the proportion of farmers without adequate inputs could on theoretical grounds implement policies such as production subsidies for input providers, public production of selected inputs, or subsidies for example in the form of payment guarantees for the inputs received by farmers in order to achieve full efficiency in the functioning of the farm input market. 


\section{References}

[1] Akiyama, T., J. Baffes, D. F. Larson, and P. Varangis, 2003, Commodity Market Reform in Africa: Some Recent Experience, Policy Research Working Paper No. 2995, World Bank.

[2] Badiane, O., Dhaneshwar, G., Goreux, L. and Masson, P., 2002, Cotton Sector Strategies in West and Central Africa, World Bank Policy Working Paper 2867, Washington, DC.

[3] Boucher, S. R., and C. Guirkinger, 2007, Risk, Wealth, and Sectoral Choice in Rural Credit Markets, American Journal of Agricultural Economics 89(4): 991-1004.

[4] Boucher, S. R., M. R. Carter, and C. Guirkinger, 2008, Risk Rationing and Wealth Effects in Credit Markets: Theory and Implications for Agricultural Development, American Journal of Agricultural Economics 90(2): 409-23.

[5] Gibbon, P., 1999, Free Competition Without Sustainable Development? Tanzanian Cotton Sector Liberalization 1994/95 to 1997/98, Journal of Development Studies $36(1): 128-150$.

[6] Goreux, L., 2003, Reforming the Cotton Sector in Sub-Saharan Africa (SSA), Africa Region Working Paper Series No. 62, World Bank, Washington, DC.

[7] Jovanovic, B., 1979, Job Matching and the Theory of Turnover, Journal of Political Economy, 87:972-990.

[8] Hardin, G., 1968, The Tragedy of the Commons, Science, 162, 1243-1248.

[9] Larsen, M. N., 2002, Is Oligopoly a Condition of Successful Privatization?, Journal of Agrarian Change, 2(2):185-205.

[10] Larsen, M. N., 2003, Re-regulating a Failed Market: The Tanzanian Cotton Sector 1999-2002, IIS Working Paper No. 03.2, Institute for International Studies, Copenhagen.

[11] McCall, B. P., 1991, A Dynamic Model of Occupational Choice, Journal of Economic Dynamics and Control, 15:387-408.

[12] Makdissi, P., and C. Téjédo, 2004, Un effet externe positif à l'embauche: L'amélioration de la connaissance de la qualité des travailleurs, Revue Économique, 55: 93-102. 
[13] Makdissi, P., and Q. Wodon, 2005, The Impact on Farmers of Privatizing Parastatal Agricultural Monopsonies, Journal of Agriculture and Food Industrial Organization, Volume 3, Article 7.

[14] Miller, R. A., 1984, Job Matching and Occupational Choice, Journal of Political Economy, 92:1086-1120.

[15] Porter, G., and K. Phillips-Howard, 1997, Comparing Contracts: An Evaluation of Contract Farming Schemes in Africa, World Development, 25(2):227-38.

[16] Poulton C., P. Gibbon, B. Hanyani-Mlambo, J. Kydd, M. N. Larsen, W. Maro, A. Osario, D. Tschirley, and B. Zulu, 2003, Competition and Coordination in Liberalized African Cotton Market Systems, mimeo, Imperial College at Wye, United Kingdom.

[17] Raikes, P., M. F. Jensen, and S. Ponte, 2000, Global Commodity Chain Analysis and the French Filiere Approach: Comparison and Critique, Economy and Society $29(3): 390-417$.

[18] Siaens, C., and Q. Wodon, 2008, Cotton Production, Poverty, and Inequality in Benin: 1992-1999, in W. G. Moseley and L. C. Gay, editors, Hanging by a Thread: Cotton, Globalization and Poverty in Africa, Ohio University Press, Athens.

[19] Whitley, J., 2003, The Gains and Losses from Agricultural Concentration: A Critical Survey of the Literature, Journal of Agricultural and Food Industrial Organization 1: Article 6. 